\title{
Indications for destructive eye surgeries at tertiary care hospital, eastern Nepal: A five years experience
}

\author{
P Lavaju', BP Badhu', S Shah ${ }^{1}$, P Upadhyaya ${ }^{2}$ \\ Department of Ophthalmology ${ }^{1}$, Department of Pathology ${ }^{2}$ \\ B.P. Koirala Institue of Health Sciences, Dharan, Nepal
}

\begin{abstract}
Background: Destructive surgery is the management option offered to patients when further retention of the globe is unlikely and can affect ocular and general morbidity. Objective: To determine the frequency and indications for destructive eye surgeries in patients attending a tertiary hospital, Eastern Nepal. Methods: A retrospective analysis of clinical records of all the patients who had undergone destructive eye surgeries from April 2008 to March 2013 at a tertiary hospital, Eastern Nepal was carried out. Patients' history, demographic characteristics and indications for the procedure were studied. Results: A total of 88 eyes of 88 patients, who had undergone destructive eye surgery, were reviewed. The mean age of the patient was 22.89 \pm 23.49 years, median 9.5 years, with a range of 1.5 months to 80 years. Male: Female ratio was 1:1.04. Enucleation was the most common surgery performed in 46 eyes (52.3\%), followed by evisceration in 30 eyes (34.1\%) and exenteration in 12 eyes (13.6\%). The destructive eye surgery in our study accounted for $51 \%$ neoplasms, $17 \%$ ocular trauma, $15.9 \%$ ocular infection, $10.2 \%$ anterior staphyloma and $5.7 \%$ painful blind eye. The most common indication for destructive eye surgery was enucleation (60.8\%) for retinoblastoma followed by evisceration (46.6\%) for open globe injury and exentration (33.3\%) for sebaceous gland carcinoma. Conclusions: Enucleation was the most common destructive eye surgery performed. Retinoblastoma, ocular trauma and sebaceous gland carcinoma were the most common indications for destructive eye surgery.
\end{abstract}

Keywords: Enucleation, evisceration, exenteration, retinoblastoma.

\section{Address for correspondence}

Dr. Poonam Lavaju

Additional Professor

Department of Ophthalmology

B.P. Koirala Institue of Health Sciences, Dharan

Email: drpoonamlavaju@yahoo.com 


\section{Introduction}

Destructive eye surgeries (DES) include exenteration, enucleation, and evisceration. The decision for DES is distressing for the patient, their relatives and the surgeons. The indication for these surgeries varies from place to place and is especially different between developing and developed countries. ${ }^{1}$ Several reports from developing countries implicated ocular infections as the most common indication for destructive eye surgeries whereas malignant tumors accounted for most of the indications in developed countries. ${ }^{2-8}$

Evisceration and enucleation are both excellent in relieving pain in a blind painful eye, recalcitrant diseases, or in improving cosmetic appearance. ${ }^{9,10}$ Evisceration is contraindicated in suspected cases of malignancy. Enucleation is the procedure of choice in advanced intraocular tumors and in cases were conservative therapy has failed. Exenteration is reserved for orbital tumors and intraocular tumors which have spread to the orbit. ${ }^{11}$

There are limited data in our context showing indications for DES. The aim of this study was to determine the frequency and indications of DES with a view to identify the preventable indications for which appropriate intervention strategies may be formulated to help reduce DES.

\section{Methods}

A retrospective review of hospital records of all patients who had undergone evisceration, exenteration or enucleation in a tertiary referral centre, Eastern Nepal from April 2008 to March 2013 (five years period) was carried out. Detailed information collected included patients demographic data, visual acuity at diagnosis, the eye affected, indications for surgery, the type of surgery performed and histopathology reports were retrieved and recorded.

Data was entered in microsoft excel and then analyzed using SPSS version 11.5. Descriptive statistics was used to summarize the characteristics of the variables. Mean, standard deviation, median and percentage were calculated. The research was conducted after getting approval from the Institute Review Committee and was done in accordance to the declaration of Helsinki.

\section{Results}

A total of 88 eyes of 88 patients had undergone destructive eye surgeries during the study period. The mean age of patients was $22.89 \pm 23.49$ years with a range of 1.5 months to 80 years while the median age was 9.5 years. There were 43 males (48.9\%) and 45 (51.1\%) females with Male: Female ratio was 1:1.04.

Forty seven cases (53.4\%) were of children below 15 years of age, 14 cases (15.9\%) 
were of age ranging from 16-35 years, 17 cases (19.3\%) were of $36-55$ years whereas only 10 cases $(11.4 \%)$ were above 55 years of age. Enucleation was the most common surgery performed in 46 eyes (52.3\%) followed by evisceration; 30 eyes (34.1\%) and exenteration in 12 eyes (13.6\%). Enucleation was the most common surgery offered in children below 15 years of age (73.91\%) [Figure 1].

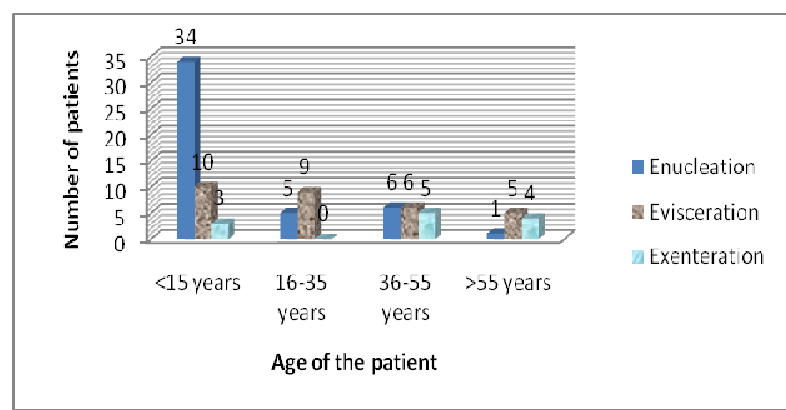

Figure 1: Distribution of destructive eye surgeries according to the age groups

Most of the eyes that underwent DES were blind; 73 cases (83\%) had a visual acuity of no perception of light while perception of light in 9 cases (10.2\%), 1/60 in 2 cases (2.3\%) of sebaceous gland carcinoma and malignant melanoma and $6 / 60$ in 1 case (1.1\%) with sebaceous gland carcinoma. One case of adenocystic carcinoma had vision of 6/24 and another case of malignant melanoma had 6/ 12.

Table 1: Indications for destructive eye surgeries in the study population

\begin{tabular}{|l|l|}
\hline \multicolumn{1}{|c|}{ Indications } & \multicolumn{1}{c|}{ Frequency (\%) } \\
\hline Neoplasm & $45(51.1 \%)$ \\
\hline Ocular Infection & $14(15.9 \%)$ \\
\hline Trauma & $15(17 \%)$ \\
\hline Anterior staphyloma & $9(15.2 \%)$ \\
\hline Painful blind eye & $5(5.7 \%)$ \\
\hline Total & $88(100 \%)$ \\
\hline
\end{tabular}

The most common indication for DES was neoplasm in 45 cases $(51 \%)$. This was followed by ocular trauma (globe perforation and rupture) in 15 cases (17\%), ocular infections (corneal ulcer and panophthalmitis) in 14 cases (15.9\%), anterior staphyolma in 9 cases $(10.2 \%)$ and painful blind eye in 5 cases(5.7\%). 
Table 2: Distribution of indications for Destructive eye surgeries according to age group and gender

\begin{tabular}{|c|c|c|c|c|c|}
\hline & \multicolumn{5}{|c|}{ Indications for destructive eye surgeries } \\
\hline & Neoplasm & $\begin{array}{c}\text { Ocular } \\
\text { infections }\end{array}$ & $\begin{array}{l}\text { Ouclar } \\
\text { trauma }\end{array}$ & $\begin{array}{c}\text { Anterior } \\
\text { staphyloma }\end{array}$ & Painful blind eye \\
\hline \multicolumn{6}{|l|}{ Sex } \\
\hline Male & 25 & 6 & 10 & 2 & 0 \\
\hline Female & 20 & 8 & 5 & 7 & 5 \\
\hline \multicolumn{6}{|c|}{ Age group (years ) } \\
\hline$<15$ & 32 & 4 & 5 & 5 & 1 \\
\hline $15-35$ & 0 & 4 & 6 & 4 & 0 \\
\hline $36-55$ & 9 & 5 & 1 & 0 & 2 \\
\hline$>55$ & 4 & 1 & 3 & 0 & 2 \\
\hline
\end{tabular}

Table 2 shows the distribution of indications for DES in various age groups and gender. Neoplasm and ocular trauma was predominant indications for DES in male. While in females, ocular infections, anterior staphyloma and painful blind eye preponderate.

The incidence of DES was more in children below 15 years of age $(53.4 \%)$ where neoplasm was the most common indication $(68 \%)$.

Neoplasms (71.7\%) accounted for the most common indication for enucleation whereas ocular trauma (46.6 \%) accounted for most common indication for evisceration. All the patients undergoing exenteration had neoplasm (100\%) [Table 3]

Table 3: Indications for destructive eye surgeries in the study population 


\begin{tabular}{|l|l|l|l|}
\hline \multicolumn{1}{|c|}{ Indications } & Enucleation (n, \%) & \multicolumn{1}{|c|}{ Evisceration (n, \%) } & \multicolumn{1}{|c|}{ Exenteration (n, \%) } \\
\hline Neoplasm & $33(71.7)$ & 0 & $12(100)$ \\
\hline Ocular infections & $2(4.3)$ & $12(40)$ & 0 \\
\hline Trauma & $1(2.1)$ & $14(46.6)$ & 0 \\
\hline Anterior staphyloma & $7(15.2)$ & $2(6.6)$ & 0 \\
\hline Painful blind eye & $3(6.5)$ & $2(6.6)$ & 0 \\
\hline Total & $46(100 \%)$ & $30(100 \%)$ & $12(100 \%)$ \\
\hline
\end{tabular}

Retinoblastoma ( $n=28,60.86 \%)$ accounted for the main indication for enucleation while the remaining were malignant melanoma $(n=4,8.6 \%)$ idiopathic myofibroblastic tumor $(\mathrm{n}=1, \quad 2.1 \%), \quad$ anterior staphyoma ( $n=9,19.5 \%$ ) phthsis bulbi $(n=3,6.5 \%)$ and painful blind eye ( $n=1,2.1 \%)$.

Trauma was the predominant indication for evisceration responsible in 14 cases (46.6\%) followed by five sloughing corneal ulcer (16.6\%), seven panophthalmitis $(23.3 \%)$ and four anterior staphyloma (13.3\%).

All the patients with ocular trauma had severe open globe injuries with globe perforation and rupture, with no visual potential. All the 12 cases who were indicated for exenterated had tumors; three cases of advanced retinoblastoma (25\%),two cases of malignant melanoma (16.6\%), four cases of sebaceous gland carcinoma (33.3\%), and one cases of adenocystic carcinaoma, squamous cell carcinoma and ocular surface squamous neoplasm (OSSN) each.

Out of 32 children below 15 years of age group with tumor, 31 had retinoblastoma
(96.8\%). In the age group between 36-55 years, five patients had malignant melanoma and one sebaceous gland carcinoma and one adenocystic carcinoma. In patients more then 55 years of age, sebaceous gland carcinoma was present in three cases and malignant melonoma in one case.

\section{Discussion}

The mean age of the patient was 22.89 years. This finding was comparable to what was reported in the literature by Bodunde et al with a mean age of 29.69 years and Musa et al (30.1 \pm 23.7 years) and $30.7 \pm 24.2$ years by Awe et al. ${ }^{12-14}$ However this was lower than the figures reported by Muhammad et al (34.4 \pm 17.7 years), Eballe et al (43.78 years) and Nwosu et al 40.8 years. ${ }^{1,2,14}$ Females were slightly more predominant than males which were different than those reported in the literature where male was more predominant. ${ }^{4,14,16,17}$

The indication for DES predominantly involved children less than 15 years of age (53.4\%). This was comparable to the findings 
in other studies. 1, 4, 13,14 Unlike our study, another study from Nepal by Pandey et al, reported that the commonest age group for DES was 61-70 years. ${ }^{4}$ This variation in age groups could be because in our study, the bulk of patients undergoing DES indicated for neoplasm comprised of children below 15 years of age. In this study, patients below 15 years age group, undergoing DES, $71.1 \%$ was indicated for tumor, $28.5 \%$ due to ocular infections, 33.3\% ocular trauma, 55.5\% anterior staphyloma and $11.1 \%$ had painful blind eye. Most of the patients are of pediatric age group which is a topic of great concern because of the psychological trauma they face throughout their long life of blindness. Mortality is another area of concern if DES were to be indicated for malignancy.

Tumor as the main indication for DES $(51.1 \%)$ was consistent with the findings from Nigeria by Muhammad (41.4\%) and Chinda et al (31\%). ${ }^{15,18}$ However, it contrasts with the findings of Pandey et al, Eballe et al and Monsudi et al who reported ocular infections as the most common indication for DES. ${ }^{1,3,4}$ The most common tumors in our study included retinoblastoma in children, sebaceous gland carcinoma in adults and elders.

According to a study, neoplasms has been reported as the most common indication $(41.4 \%)$ for DES and a high proportion of patient among $<5$ years presented with retinoblastoma. ${ }^{15}$

Open globe injury was the second most common indication accounting 17\%. All these patients either had unrepairable globe perforation and rupture without any visual potential. Some studies have shown trauma as the most common indication accounting $36.2 \%$ to $43.8 \%$. $^{12-15}$ Ocular injuries was predominantly encountered in male population (66.6\%), comparable to other studies. ${ }^{3,4,15}$ Male are more exposed to outdoor and hazardous occupations predisposing them to ocular injuries.

Pandey et al reported $4.88 \%$ for DES for crush injuries in their study. ${ }^{4}$ This highlights the need of educating people regarding ocular injuries and the preventive measures, so as to decrease the burden of ocular morbidity due to ocular injuries.

Ocular infections was the third most indication in this study (15.9\%), predominant in age group between 35-55 years. Seven, six and one cases of panophthalmitis, corneal ulcer and anterior staphyloma respectively, constituted the cases of ocular infection that indicated evisceration.

Musa et al reported $18.4 \%$ cases undergoing DES were due to ocular infections. Eight (61.5\%), $4(30.8 \%)$ and $1(7.7 \%)$ cases of panophthalmitis, endophthalmitis and perforated infective corneal ulcers respectively constituted the 13 cases of 
ocular infection that underwent enucleation. Six (28.6\%), 8 (38.1\%) and 7 (33.3\%) cases of panophthalmitis, endophthalmitis and perforated infective corneal ulcers respectively constituted the 21 cases of ocular infection that underwent evisceration. 13

In this study, tumor was the most common indication $(51.1 \%)$ requiring DES, where enucleation was performed. This was consistent with reports by Awe et al (50\% underwent enucleation). Unlike ours, other studies have reported evisceration to be the most common intervention carried out. 1, 4, 3, 13, 15, 18 This difference may be due to the variable presentations of ocular entities requiring DES which vary from one place to another.

Since DES carries a great weight with regard to psychological aspects and social acceptance, preventive measures can be assured rather than DES in cases of nonneoplastic origin in order to decrease the burden of DES. Lack of health awareness, socioeconomic constrains and inaccessibility could be depriving them from recieving early intervention, leading to DES. Education of people on ocular trauma, infections, occupational hazards and improving health facilities can help reduce incidence of DES. There is a need for eye health education to create awareness, encourage early presentation to the hospital and use of protective measures to prevent ocular injuries.

\section{References}

1. Eballé AO, Dohvoma VA, Koki G, Oumarou A, Bella AL, Mvogo CE.Indications for destructive eye surgeries at the Yaounde GynaecoObstetric and Paediatric Hospital. Clin Ophthalmol 2011; 5:561-5.

2. Nwosu SN. Destructive ophthalmic surgical procedures in Onitsha, Nigeria. Niger Postgrad Med J 2005; 12:53-6.

3. Monsudi KF, Ayanniyi AA, Balarabe AH. Indications for destructive ocular surgeries in Nigeria. Nepal $J$ Ophthalmol 2013; 5:24-7.

4. Pandey PR. A profile of destructive surgery in Nepal Eye Hospital. Kathmandu Univ Med J (KUMJ) 2006; 4:65-9.

5. Günalp I, Gündüz K, Ozkan M. Causes of enucleation: $A$ clinicopathological study. Eur J Ophthalmol 1997; 7:223-8.

6. Scat $Y$, Liotet S, Bellefqih S. Etiology of enucleations. Apropos of 3,246 cases. J Fr Ophtalmol 1996; 19: 242-7.

7. Setlur VJ, Parikh JG, Rao NA. Changing causes of enucleation over the past 60 years. Graefes Arch Clin Exp Ophthalmol 2010; 248:593-7. 
8. Stiebel H, Sela M, Pe'er J. Changing indications for enucleations in Hadassah University Hospital, 1960-1989. Ophthalmic Epidemiol 1995; 2:123-7.

9. Migliori ME. Enucleation versus evisceration. Curr Opin Ophthalmol. 2002; 13(5):298-302.

10. Shah-Desai SD, Tyers AG, Manners RM. Painful blind eye: efficacy of enucleation and evisceration in resolving ocular pain. $\mathrm{Br} \mathrm{J}$ Ophthalmol. 2000; 84(4):437-438.

11. Holdy JB, Chang WJ, Dailey RA, Foster JA. Orbit, eyelids and lacrimal system. In: Basic and Clinical Science Course.San Francisco: American Academy of Ophthalmology; 2010: 123-32.

12. Bodunde OT, Ajibode HA, Awodein OG. Destructive eye surgeries in Sagamu. Niger Med Pract 2005; 48:47-9

13. Musa KO, Aribaba OT, Onakoya AO, Rotimi-Samuel A, Akinsola FB. Indications for destructive eye surgeries at a Nigerian tertiary eye care centre: A ten-year review. Niger Postgrad Med J 2016; 23:12-6.

14. Awe OO, Adeoye $\mathrm{AO}$, Onakpoya $\mathrm{OH}$. Surgical eye removal in lle-lfe, Nigeria. Niger J Ophthalmol 2016; 24:31-4.

15. Muhammad AD, Muhammad N. Indications for destructive eye surgeries in Sokoto, North Western Nigeria. Sudanese J Ophthalmol 2015; 7:41-4.

16. Monsudi KF, Ayanniyi AA, Balarabe $\mathrm{AH}$. Indications for destructive ocular surgeries in Nigeria. Nepal J Ophthalmol 2013; 5:24-7.

17. Ibanga $A$, Asana $U$, Nkanga $D$, Duke $R$, Etim B, Oworu O. Indications for eye removal in southern Nigeria. Int Ophthalmol 2013; 33:355-60.

18. Chinda D, Abah ER, Rafindadi AL, Samaila E. Changing trend in the causes of destructive eye surgery at Guinness Ophthalmic Unit, Ahmadu Bello University Teaching Hospital, Kaduna, Nigeria. Ann Nigerian Med 2010;4:62-5. 